\title{
SUPERVASMOL POISONING: AN EMERGING ENT EMERGENCY
}

\author{
Mitta Sreenivasulu1, Lanke Sowmya², Bhennur Durga Prasad ${ }^{3}$
}

${ }^{1}$ Associate Professor, Department of ENT, Narayana Medical College, Nellore.

${ }^{2}$ Assistant Professor, Department of ENT, Santhiram Medical College, Nandyal.

${ }^{3}$ Assistant Professor, Department of ENT, Santhiram Medical College, Nandyal.

\section{ABSTRACT}

Poisoning is one of the commonest modes of suicide in India. Supervasmol poisoning is one of the commonest modes of suicidal attempt in our region. The common cause for consumption of hair dye is by suicidal intent or accidental oral ingestion. There is no specific antidote for Supervasmol poisoning. Management is only symptomatic and supportive with emergency tracheostomy in majority of cases. Hence, we conducted this study to emphasize the role of ENT surgeon in Supervasmol poisoning.

\section{STUDY DESIGN}

Prospective study.

\section{MATERIALS AND METHODS}

We present a total of 79 cases of Supervasmol poisoning who attended the Emergency Department of Narayana Medical College and General Hospital, Nellore.

\section{RESULTS}

All patients were between age group 15-35 yrs. Females are more than males. More patients were in second decade; 55 cases presented in acute phase, 51 patients underwent tracheostomy and four patients were brought dead.

\section{CONCLUSION}

Emergency tracheostomy is a life saving measure in severe stridor.

\section{KEYWORDS}

Supervasmol, Suicide, Paraphenylenediamine, Tracheostomy.

HOW TO CITE THIS ARTICLE: Sreenivasulu M, Sowmya L, Prasad BD. Supervasmol poisoning - an emerging ENT emergency. J. Evolution Med. Dent. Sci. 2016;5(38):2311-2313, DOI: 10.14260/jemds/2016/537

\section{INTRODUCTION}

Supervasmol 33 is an emulsion based hair dye commonly used in India. The constituents of this hair dye include Paraphenylenediamine (PPD) (4\%), resorcinol, propylene glycol, Ethylenediaminetetraacetic Acid (EDTA), sodium, liquid paraffin, cetostearyl alcohol, sodium lauryl sulphate, herbal extracts, preservatives and perfumes. ${ }^{1}$ The major lifethreatening compound in this hair dye is Paraphenylenediamine (PPD). ${ }^{2}$ Concentration of PPD in different hair dyes range from $0.2 \%$ to $3.75 \%$, which give colour from golden blonde to black colour. ${ }^{3}$ The hair dye is extremely cheap and freely available, making it an attractive option for suicidal intent. ${ }^{4}$ Toxic effects of PPD are dose related. ${ }^{5}$ The degree of the tissue damage is related to the dose of the poison, but the exact concentration that causes toxicity is not known. ${ }^{6}$ 3-4 gm of PPD causes systemic poisoning and 7 to $10 \mathrm{gm}$ is the lethal dose. Ingestion of $100 \mathrm{~mL}$ of Supervasmol 33 dye, which is equal to $12 \mathrm{gm}$ of PPD can lead to severe complications like laryngeal oedema, acute renal failure and rhabdomyolysis. ${ }^{7}$

Systemic features of PPD poisoning occur in three phases. Phase 1 is an acute presentation with oedema of neck,

Financial or Other, Competing Interest: None.

Submission 10-03-2016, Peer Review 22-04-2016,

Acceptance 28-04-2016, Published 12-05-2016.

Corresponding Author:

Lanke Sowmya,

Assistant Professor,

Department of ENT,

Santhiram Medical College,

Nandyal.

E-mail: lakesowmya@gmail.com

DOI: $10.14260 /$ jemds $/ 2016 / 537$ airway obstruction, gastritis and severe vomiting. Phase 2 is a subacute presentation with Acute Renal Failure (ARF), rhabdomyolysis and haemolysis. Phase 3 progresses to multiorgan failure.

\section{MATERIALS AND METHODS}

A prospective study was carried out addressing 79 patients of Supervasmol poisoning over a period of two years in our hospital. This study reveals the importance of early surgical intervention in the form of life saving tracheostomy in a patient of Supervasmol poisoning with stridor.

\section{RESULTS}

This prospective study included 79 patients of Supervasmol poisoning who attended Narayana Medical College, Nellore, over a period of two years. It was observed that all patients were between age group of 15-35 years. Females are more than males; 19 patients were male and 60 patients were female (Table No. 1); 47 patients were in second decade, 24 patients in third decade and 8 patients were in first decade. It was observed that more number of patients were in second decade (Table No. 2); 70\% of patients presented in acute phase with severe orofacial oedema (Fig No. 1 and 2) and 30\% of patients had laryngeal oedema not responding to steroids (Fig No. 4); 55 cases presented in acute phase, 51 patients underwent tracheostomy and 4 patients were brought dead (Table 3). Tracheostomy was done in cases where intubation was difficult (Fig. No. 3). All patients who underwent tracheostomy were rescued from death due to acute respiratory obstruction (Fig. No. 5). 


\begin{tabular}{|c|c|}
\hline Males & Females \\
\hline 19 & 60 \\
\hline Table 1: Sex Distribution of Patients \\
\hline
\end{tabular}

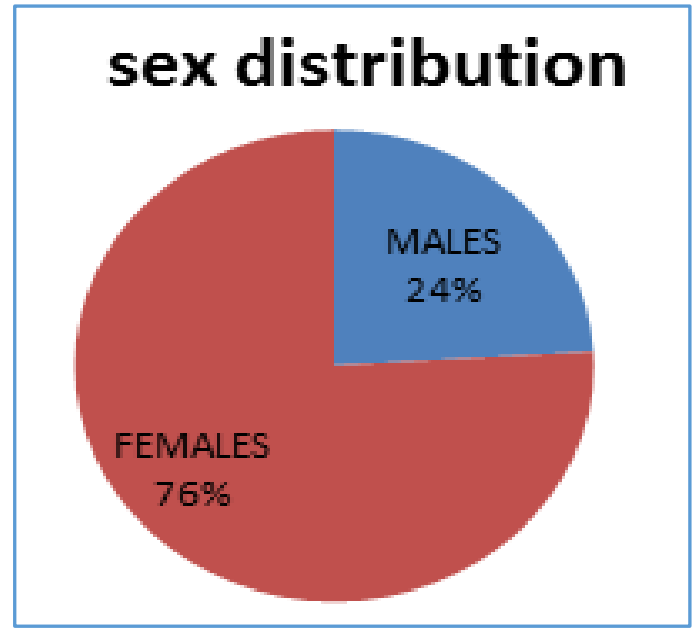

PIE Diagram Showing Sex Distribution of Patients

\begin{tabular}{|c|c|c|}
\hline First Decade & Second Decade & Third Decade \\
\hline 8 & 47 & 24 \\
\hline \multicolumn{2}{|c|}{ Table 2: Age Distribution of Patients } \\
\hline
\end{tabular}

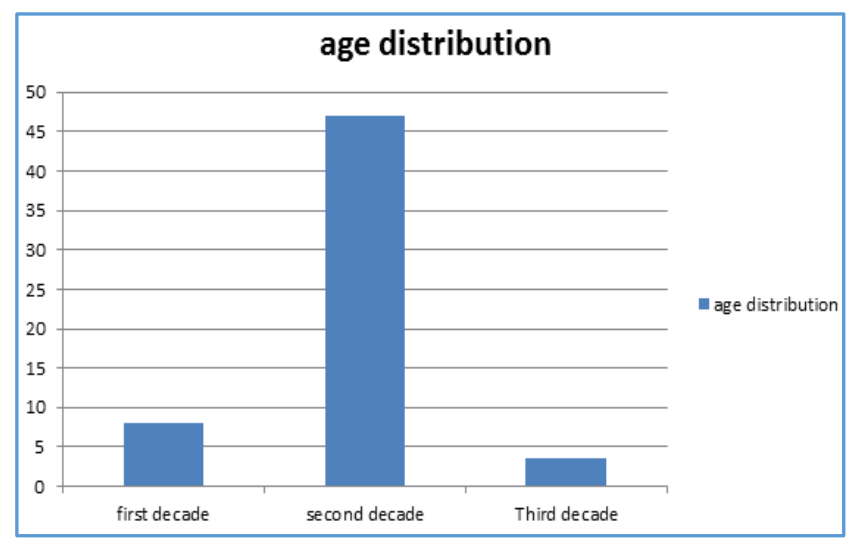

Bar Diagram Showing Age Distribution of Patients

\begin{tabular}{|c|c|}
\hline No. of Patients Presented in Acute Phase & 55 \\
\hline No. of Patients Underwent Tracheostomy & 51 \\
\hline No. of Patients Brought Dead & 4 \\
\hline \multicolumn{2}{|c|}{ Table 3: Presenting Status of Patients } \\
\hline
\end{tabular}

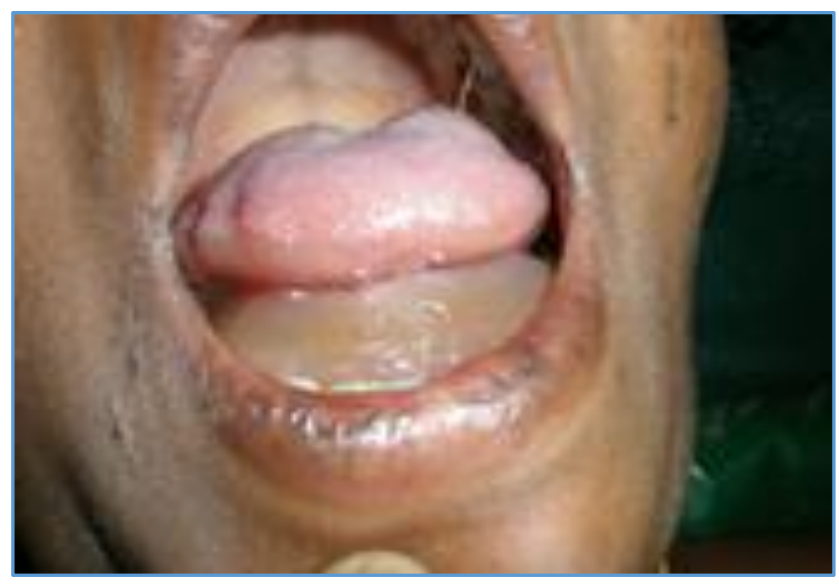

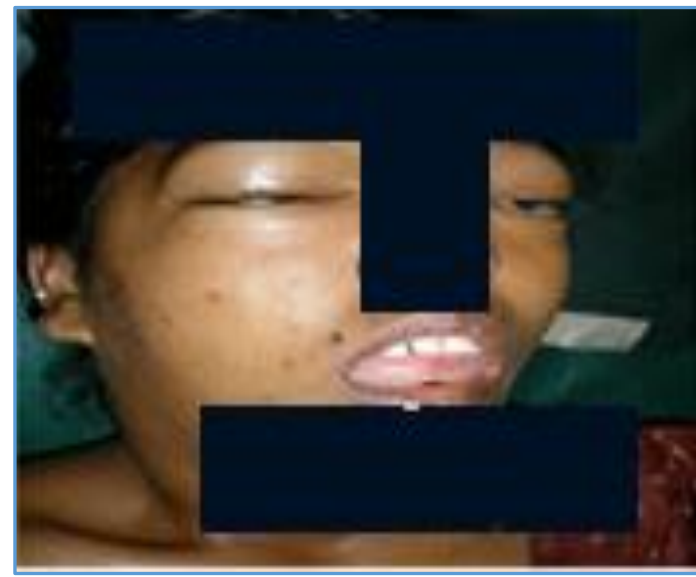

Fig. 1 \& 2: Patient with Severe Orofacial Oedema

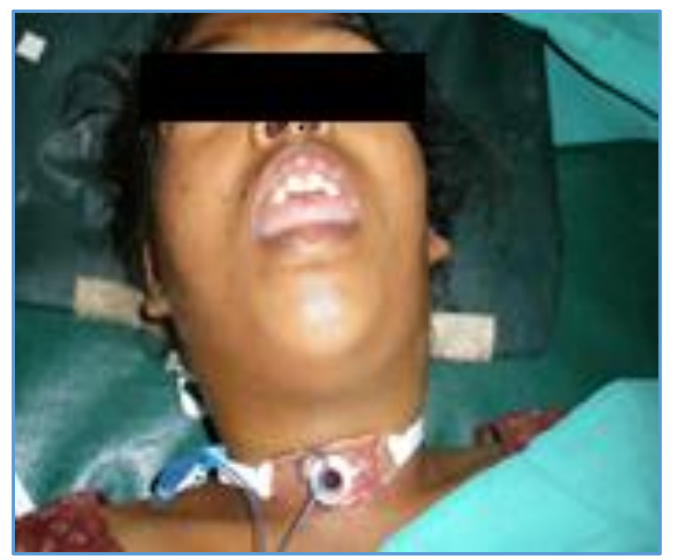

Fig. 3: Patient Underwent Tracheostomy

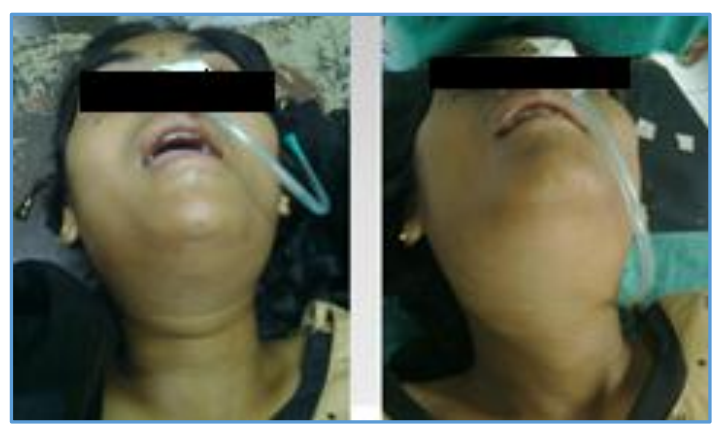

Fig. 4: Hair Dye Poisoning

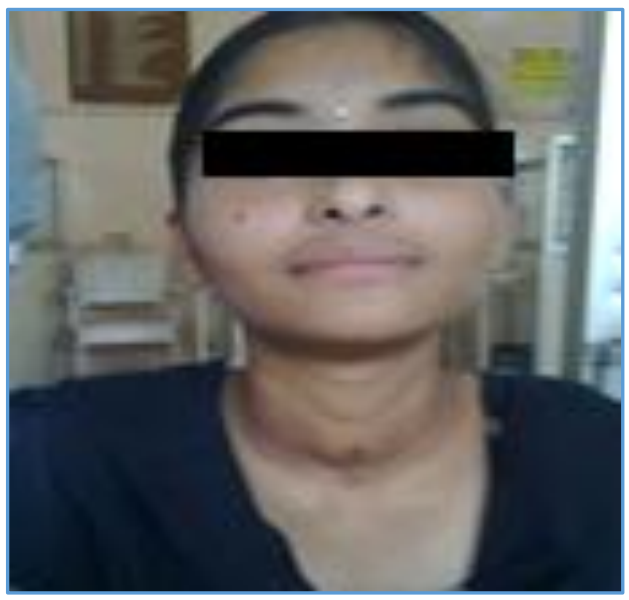

Fig. 5: After Decannulation and Recovery 


\section{DISCUSSION}

Hair dye poisoning is an uncommon form of intoxication in the west. ${ }^{8}$ Hair dye poisoning is common mode of intoxication in our region. The constituents of this hair dye include PPD (4\%), resorcinol, propylene glycol, ethylenediaminetetraacetic acid, sodium liquid paraffin, sodium lauryl sulphate, preservatives and perfumes. ${ }^{1}$ Accidental or intentional poisoning results in systemic toxicity in a dose dependent manner. The main toxicities of this compound include severe oedema of the face and neck frequently requiring emergency tracheostomy. ${ }^{9,10}$ In a retrospective study over a period of 7 years (2001-2008) conducted in Egypt, 25 cases of PPD poisoning were identified.11,12 In the present study which is a two-year prospective study, 79 cases of PPD poisoning were analysed. In this study, maximum incidence was observed in $2^{\text {nd }}$ and $3^{\text {rd }}$ decades which are correlating with the study of PK Jain et al. In this study, there was female preponderance $76 \%$ which is correlating with the studies done by Ayoub Filali et al ${ }^{8} \mathrm{M}$. Hamdouk. $^{2}$ and PK Jain et al. ${ }^{13}$ In this study, most reported cases were from adolescents and adults which correlates with the eleven year retrospective study done in Morocco on 374 cases and 10-year study period done in Sudan on 3159 patients. ${ }^{3}$

Ingestion of PPD results in acute poisoning with major systemic problem resulting in multisystem involvement of CNS, CVS and musculoskeletal. High mortality rate was noticed with this poisoning. ${ }^{14}$

\section{CONCLUSION}

The Supervasmol poisoning is a common mode of suicidal attempt in our region. Death in Supervasmol poisoning may be due to respiratory obstruction, angioneurotic oedema of larynx, oedema of floor of the mouth and base of the tongue or due to systemic complications. Delay in hospitalization may result in death of the patients. Emergency tracheostomy is a life saving measure in severe stridor.

\section{REFERENCES}

1. Nohynek GJ, Fautz R, Benech-Kieffer F, et al. Toxicity and human health risk of hair dyes. Food and Chemical Toxicology 2004;42(4):517-543.

2. Mohamed I Hamdouk, Mohamed B Abdelraheem, Ahbab A Taha, et al. Paraphenylene diamine hair dye poisoning. Clinical Nephrotoxins 2008;3:871-879.
3. Mohamed AR, Mohamed Hamdouk, Eduard E Zijlstra. Paraphenylene diamine (hair dye) poisoning in children. Arab Journal of Nephrology and Transplantation 2010;3(1):39-43.

4. Jain PK, Agarwal N, Sharma AK, et al. Prospective study of ingestional hair dye poisoning in northern India (Prohina). Journal of Clinical Medicine and Research 2011;3(1):9-19.

5. Sumeet Singla, Sanjeev Miglani, Lal AK, et al. Paraphenylenediamine (PPD) Poisoning. JIACM 2005;6(3):236-238.

6. Rajendra Prasad N, Aparna Rajeshwar Rao B, Suchitra M $\mathrm{M}$, et al. A retrospective study on the biochemical profile of self poisoning with a popular indian hair dye. Journal of Clinical and Diagnostic Research 2011;5(7 Suppl2):1343-1346.

7. Krishnaswamy SK, Yesudas S, Rajappannair Prabha Ajeshkumar, Amol Ramesh Mahaldar, et al. Rhabdomyolysis due to hair dye poisoning. IJCCM 2007;11(4):212- 214.

8. Filali A, Semlali I, Ottaviano V, et al. A retrospective study of acute poisoning of paraphenylenediamine (occidental tawakt) in Morocco. Afr J Trad CAM 2006;3(1):142-149.

9. Ashraf W, Dawling S, Farrow LJ. Systemic paraphenylenediamine poisoning: a case report and review. Hum Exp Toxicol 1994;13(3):167-170.

10. Lava NS, Dollar J. Hair dye induced rhabdomyolysis. J Electroencephalogr Clin Neurophysiol 1996;98:18.

11. Soni Sachin S, Nagarik Amit P, Dinaker Manjunath, et al. Systemic toxicity of paraphenylenediamine. Indian Journal of Medical Sciences 2009;63(4):164-166.

12. Sawsan Shalaby A, Mohy Elmasry K, Amany AbdElrahman E, et al. Clinical profile of acute para phenylene diamine intoxication in Egypt. Toxicology and Industrial Health 2010;26(2):81-87.

13. Jain PK, Agarwal N, Kumar P, et al. Hair dye poisoning in Bundelkhand region. JAPI 2011;59:415-418.

14. Chugh KS, Malik GH, Singhal PC. Acute renal failure following paraphenylene diamine (hair dye) poisoning: report of two cases. J Med 1982;13(1-2):131-137. 